\title{
Original Research Manuscript
}

Association of moderate-to-vigorous physical activity with neck circumference in eight Latin American countries

Brief running head: Moderate-to-vigorous physical activity and neck circumference.

Authors: Gerson Luis de Moraes Ferrari ${ }^{1,2^{*}}$, Irina Kovalskys ${ }^{3}$, Mauro Fisberg ${ }^{4,5}$, Georgina Gómez Salas ${ }^{6}$, Attilio Rigotti ${ }^{7}$, Lilia Yadira Cortés Sanabria ${ }^{8}$, Martha Cecilia Yépez García ${ }^{9}$, Rossina Gabriella Pareja Torres ${ }^{10}$, Marianella HerreraCuenca ${ }^{11}$, Ioná Zalcman Zimberg ${ }^{12}$, Viviana Guajardo ${ }^{13}$, Michael Pratt ${ }^{14}$, Carlos Pires ${ }^{15}$, and Dirceu Solé ${ }^{2}$ on behalf of the ELANS Study Group ${ }^{\ddagger}$

${ }^{1}$ Centro de Investigación en Fisiologia del Ejercicio-CIFE, Universidad Mayor, Santiago, Chile. E-mail: gersonferrari08@yahoo.com.br.

2Disciplina de Alergia, Imunologia Clínica e Reumatologia do Departamento de Pediatria da Universidade Federal de São Paulo, São Paulo, Brazil.

${ }^{3}$ Commitee of Nutrition and Wellbeing, International Life Science Institute, Buenos Aires, Argentina. E-mail: ikovalskys@gmail.com.

${ }^{4}$ Instituto Pensi, Fundação José Luiz Egydio Setubal, Hospital Infantil Sabará, São Paulo, Brazil. E-mail: mauro.fisberg@gmail.com.

${ }^{5}$ Departamento de Pediatria da Universidade Federal de São Paulo, São Paulo, Brazil. E-mail: mauro.fisberg@gmail.com.

${ }^{6}$ Departamento de Bioquímica, Escuela de Medicina, Universidad de Costa Rica, San José, Costa Rica. E-mail: georgina.gomez@ucr.ac.cr.

${ }^{7}$ Centro de Nutrición Molecular y Enfermedades Crónicas, Departamento de Nutrición, Diabetes y Metabolismo, Escuela de Medicina, Pontificia Universidad Católica, Santiago, Chile. E-mail: arigotti@med.puc.cl.

${ }^{8}$ Departamento de Nutrición y Bioquímica, Pontificia Universidad Javeriana, Bogotá, Colombia. E-mail: ycortes@javeriana.edu.co. 
${ }^{9}$ Colégio de Ciencias de la Salud, Universidad San Francisco de Quito, Quito, Ecuador. E-mail: myepez@usfq.edu.ec.

${ }^{10}$ Instituto de Investigación Nutricional, La Molina, Lima, Peru. E-mail: rpareja@iin.sld.pe.

${ }^{11}$ Centro de Estudios del Desarrollo, Universidad Central de Venezuela/Fundación Bengoa, Caracas, Venezuela. E-mail: marianella.herrera@ucv.ve.

${ }^{12}$ Departamento de Psicobiologia, Universidade Federal de São Paulo, São Paulo, Brazil. E-mail: iona.zimberg@gmail.com.

${ }^{13}$ Commitee of Nutrition and Wellbeing, International Life Science Institute, Buenos Aires, Argentina. E-mail: vbguajardo@gmail.com.

${ }^{14}$ Nutrition and Health Sciences Program, Hubert Department of Global Health, Rollins School of Public Health, Emory University, Atlanta, USA. E-mail: michael.pratt@emory.edu.

${ }^{15}$ Centre for Mathematics of the University of Trás-os-Montes e Alto Douro (CMUTAD), Vila Real, Portugal. E-mail: carlosandrepires@gmail.com.

¥Membership of the ELANS Study Group is provided in the Acknowledgments section of the manuscript.

Corresponding author: Gerson Luis de Moraes Ferrari

Rua Otonis, 725 Vila Clementino, 04025-002-São Paulo-S.P.-Brazil

E-mail: gersonferrari08@yahoo.com.br.

Abstract, 199; main text, 3215; tables, 5; references: 69 


\section{Abstract}

The present study investigated the association of accelerometer-determined moderate-to-vigorous physical activity (MVPA) with neck circumference (NC) in adolescents and adults from eight Latin American countries. The sample consisted of 2370 participants from the Latin American Study of Nutrition and Health, a multicenter cross-sectional nutrition and health surveillance study of a nationally representative sample from eight Latin American countries. An Actigraph GT3X+ accelerometer was used to monitor MVPA. Adolescents were categorized as NC $>34.25 \mathrm{~cm}$ in boys and $\mathrm{NC}>31.25 \mathrm{~cm}$ in girls, and adults were categorized as $\mathrm{NC}>39 \mathrm{~cm}$ in men and $\mathrm{NC}>35 \mathrm{~cm}$ in women. The average time of MVPA was $34.88 \mathrm{~min} /$ day, ranging from 31.16 in Venezuela to 40.27 in Chile. Concerning NC, $37.0 \%$ of the sample was classified as having elevated NC. Chile was the country with the highest percentage of people with elevated NC (56.9\%), and Colombia had the lowest percentage $(24.8 \%)$. Overall, the MVPA (min/day) was associated with elevated NC (OR $=0.994$, Cl95\% $=0.990-0.998)$. In Costa Rica and Peru, there were significant associations between MVPA and NC when analyzed by country. Further research is required to understand the differences between countries in the observed associations.

Keywords: physical activity, accelerometer, neck circumference, obesity, body composition, anthropometric. 


\section{Introduction}

The prevalence of overweight and obesity is a major global health concern [1] that now extends beyond high-income nations to low- and middleincome nations [2]. Obesity is associated with cardiovascular risk factors such as type II diabetes, insulin resistance, hypertension, and elevated triglyceride and cholesterol levels [3-5]. The presence of cardiovascular disease (CVD) risk factors is associated with premature death [6]. Consequently, early detection of obesity is crucial to preventing adverse long-term effects on individuals' health $[5]$.

The fat located in the central region, visceral or subcutaneous, is strongly linked to the risk of developing diseases. It has been discussed in the literature that other mechanisms or other deposits of fat and visceral fat may also contribute to the development of risk factors for CVD [7]. Upper-body subcutaneous fat estimated by neck circumference (NC) may be linked to a higher metabolic risk than abdominal visceral fat. NC is a simple, convenient but less used anthropometric measure correlated with waist circumference (WC) and body mass index (BMI) and has been associated with components of metabolic syndrome in cross-sectional [8-10] and cohort studies [11-12]. NC may likely be a very convenient and valid alternative measure of obesity and may even be a better marker of metabolic risk than standard measures such as BMI and WC [9].

Physical activity, a cornerstone in the prevention and treatment of obesity and CVD, has been shown to be inversely related to fatness $[13,14]$. The prevalence of physical inactivity in Latin America (LA) was reported the highest worldwide [15] and ranked fifth as a risk factor for mortality in the Southern 
Cone of LA [16]. LA is the most urbanized region in the world ( $80 \%$ of its population lives in cities) [17] and has rising prevalence of obesity, chronic diseases, and physical inactivity $[18,19]$. Obesity and physical inactivity are now especially important public health challenges in LA [20].

The objective assessment of moderate-to-vigorous physical activity (MVPA) using accelerometers has become more common practice in research originating from high-income countries [14,21]. In contrast, given the cost associated with using objective measures like accelerometers and the lack of research in this field in most LA countries [22], there are relatively few studies using this technology in LA countries [23]. To our knowledge, there has been no examination of the association between objective assessment of MVPA using accelerometers with NC in a nationally representative sample from LA. Thus, the purpose of this article is to investigate the association of accelerometerdetermined MVPA with NC in adolescents and adults from eight LA countries.

\section{Materials and Methods}

Participants

The Latin American Study of Nutrition and Health (Estudio Latinoamericano de Nutrición y Salud; ELANS) is a household populationbased multi-national cross-sectional survey aimed at (1) providing up-to-date reliable and comparable data of dietary intake, PA, and its association with anthropometric profile among representative urban populations of eight LA countries; (2) measuring variation in overweight, dietary intake, and PA by region, cultural background, socioeconomic status, age, and gender; and (3) 
adding new scientific-based evidence to describe the interplay among energy intake, energy expenditure, and anthropometric measurements.

The ELANS involves eight LA countries (Argentina, Brazil, Chile, Colombia, Costa Rica, Ecuador, Peru, and Venezuela) representing a total of 9218 individuals, aged 15-65 years, stratified by geographical location (only urban areas), gender, age, and socioeconomic level (SEL). The rationale and design of the study are reported in more detail elsewhere [24]. The overarching ELANS protocol was approved by the Western Institutional Review Board (\#20140605) and is registered at Clinical Trials (\#NCT02226627). Additional site-specific protocols were also approved by the ethical review boards of the participating institutions. All participants provided informed consent/assent for participation in their country-level study.

\section{Accelerometer}

To objectively monitor MVPA, $40 \%$ of the sample was asked to wear a triaxial accelerometer (model GT3X+, ActiGraph, Pensacola, FL, USA) on an elasticized belt at hip level on the right mid-axillary line for 7 days. The participants were asked to wear the device while they are awake and to take it off for sleeping, showering, or swimming. Verbal (in person and by demonstration) and written instructions on how to wear the accelerometer were provided. To further ensure protocol compliance, participants filled in an accelerometer log indicating the start and end time of use per day. The participants were encouraged to wear the accelerometer 12 hours/day for at least 7 days, including 2 weekend days. The minimal amount of accelerometer data considered acceptable for analytical purposes was 5 days (including at 
least 1 weekend day) with at least 10 hours/day of wear time following the removal of sleep time $[25,26]$. After exclusion of the nocturnal sleep period time, waking nonwear time was defined as any sequence of at least 60 consecutive minutes of zero activity counts.

On the eighth day of data collection, the research team went to the house of the participants to remove accelerometers. The research team found that the data were completed using the latest version of Actilife software (version 6.0; ActiGraph, Pensacola, FL) available. Data were collected at a sampling rate of $30 \mathrm{~Hz}$ and downloaded in periods of 60 seconds [27].

We chose to use the accelerometer activity count cut-points established by Freedson et al. [28] for counts/min. The cut-points capture the sporadic nature of activity and provide the best classification accuracy among the currently available cut-points for physical activity. Specifically, moderate physical activity was defined as time accumulated at $\geq 1952-5724$ activity counts/min, $\geq 5725$ activity counts/min for vigorous physical activity, and $\geq 1952$ activity counts/min for MVPA [28]. Because total counts/min are more appropriate measures of energy expenditure than MVPA (since these are categorized based on cut-points), accelerometer counts/min were also used as an outcome measure in the present paper. Reliability and validity of accelerometers have been documented extensively [29-31].

Neck circumference

NC (in centimeters) was measured at the point just below the larynx (thyroid cartilage) and perpendicular to the long axis of the neck (with the tape line in the front of the neck at the same height as the tape line at the back of the 
neck) using an inelastic tape measure [32]. Each measurement was repeated twice to ensure accuracy, and the average was used for the analyses. If the two readings differed by more than the previously established set point $(0.5 \mathrm{~cm}$ for $\mathrm{NC}$ ), then a third measurement was taken. All three measurements were recorded, and the outlier was excluded during the data cleaning process. Adolescents were categorized as NC $>34.25 \mathrm{~cm}$ in boys and $\mathrm{NC}>31.25 \mathrm{~cm}$ in girls [8], and adults were categorized as $\mathrm{NC}>39 \mathrm{~cm}$ in men and $\mathrm{NC}>35 \mathrm{~cm}$ in women [33]. These cut-points are probably the best to determine individuals with central obesity and metabolic syndrome [8,33]. The interviewers were trained to collect all measurements by certified nutritionists/dietitians who simultaneously operated as supervisors of the fieldwork.

Sociodemographic and SEL variables

A questionnaire was used to collect information about demographics such as age, gender, years of education, race/ethnicity, and marital status. SEL was also evaluated by questionnaire using a format based on the national indexes used in each country [34-41]. SEL data were divided into three strata (low, medium, and high). Individuals were asked about sex, age, and education level (basic or lower, high school and, university degree). These sociodemographic variables were included as covariates in all statistical models.

Statistical analyses

Statistical analyses were carried out using the $R$ software [42]. A Kolmogorov-Smirnov test was applied to evaluate the data distribution. Mean, 
standard deviation, and frequencies were computed to describe the variables studied.

Multilevel logistic models, including country and region as random effects and adjusted for sex, age, SEL, and educational level, were used to study the association between MVPA (min/day) and NC (dependent variable: normal or elevated). Multilevel models were carried out using the $\mathrm{R}$ package Ime4 [43]. A significance level of $5 \%$ was set.

\section{Results}

The sample included 2370 participants who used the accelerometer, which represented $29.6 \%$ of the total sample of the ELANS project $(n=9218)$. There were no significant differences between the participants who used the accelerometer and those who did not concerning sex $(p=0.937)$, SEL $(p=$ $0.501)$, or educational level $(p=0.235)$. However, the distribution by age group was different $(p=0.018)$; the participants with accelerometer were slightly older.

The participants used the accelerometer between 5 and 7 days. On average, the accelerometer was used for 15.3 hours/day, which represented a total time of 100.7 hours. This time ranged from 14.8 hours/day in Costa Rica to 15.8 hours/day in Peru (Table 1). 
Table 1. Descriptive analysis (Mean and SD) of accelerometer-derived data of adolescents and adults from eight Latin America countries.

\begin{tabular}{lcccc}
\hline Country & $\mathbf{N}$ & $\begin{array}{c}\text { Days/week } \\
\text { M (SD) }\end{array}$ & $\begin{array}{c}\text { Total time (hours) } \\
\text { M (SD) }\end{array}$ & $\begin{array}{c}\text { Average time/day } \\
\text { (hours) } \\
\text { M (SD) }\end{array}$ \\
\hline Argentina & 293 & $6.6(0.6)$ & $102.2(18.5)$ & $15.4(2.1)$ \\
Brazil & 563 & $6.4(0.7)$ & $97.7(17.5)$ & $15.2(2.0)$ \\
Chile & 297 & $6.7(0.6)$ & $102.2(16.4)$ & $15.3(1.8)$ \\
Colombia & 339 & $6.6(0.5)$ & $100.3(15.1)$ & $15.1(1.7)$ \\
Costa Rica & 273 & $6.7(0.6)$ & $99.4(17.0)$ & $14.8(1.9)$ \\
Ecuador & 268 & $6.8(0.5)$ & $104.9(14.1)$ & $15.5(1.7)$ \\
Peru & 330 & $6.5(0.6)$ & $103.0(15.9)$ & $15.8(1.8)$ \\
Venezuela & 367 & $6.5(0.6)$ & $98.8(16.3)$ & $15.2(1.8)$ \\
\hline Full sample & $\mathbf{2 7 3 0}$ & $\mathbf{6 . 6 ( 0 . 6 )}$ & $\mathbf{1 0 0 . 7 ( 1 6 . 6 )}$ & $\mathbf{1 5 . 3 ( 1 . 9 )}$ \\
\hline
\end{tabular}

M: mean; SD: standard deviation.

There were slightly more female $(52.2 \%)$ than male $(47.8 \%)$ participants. About 2 out of 3 participants were aged from 20 to 49 years old (65.8\%). About half $(51.2 \%)$ were from low SEL, and more than half $(60.1 \%)$ had a basic educational level or lower. Only $10.0 \%$ were from a high SEL, and $10.2 \%$ had a university degree (Table 2).

Table 2. Descriptive analysis (\%) of sample profile concerning sex, age group, socioeconomic, and educational level of adolescents and adults from eight Latin America countries.

\begin{tabular}{|c|c|c|c|c|c|c|c|c|c|c|c|c|c|}
\hline \multirow[b]{2}{*}{ Country } & \multirow[b]{2}{*}{$\mathbf{N}$} & \multicolumn{2}{|c|}{$\operatorname{Sex}(\%)$} & \multicolumn{4}{|c|}{ Age group (\%) } & \multicolumn{3}{|c|}{$\begin{array}{c}\text { Socioeconomic } \\
\text { level }(\%)\end{array}$} & \multicolumn{3}{|c|}{$\begin{array}{c}\begin{array}{c}\text { Educational level } \\
(\%)\end{array} \\
\end{array}$} \\
\hline & & $\frac{0}{\frac{0}{\pi}}$ & $\begin{array}{l}\frac{0}{\widetilde{J}} \\
\frac{\varepsilon}{\Phi} \\
\amalg\end{array}$ & 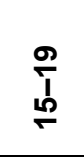 & ঙ্ণ & 守 & $\begin{array}{l}n \\
0 \\
1 \\
0\end{array}$ & 3 & $\begin{array}{l}\frac{E}{J} \\
\frac{. \bar{z}}{0} \\
\sum\end{array}$ & 음 & 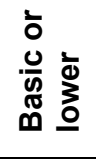 & 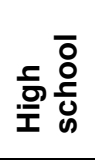 & 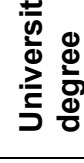 \\
\hline Argentina & 293 & 44.4 & 55.6 & 10.6 & 30.7 & 33.1 & 25.6 & 53.9 & 41.3 & 4.8 & 73.7 & 23.9 & 2.4 \\
\hline Brazil & 563 & 46.2 & 53.8 & 11.0 & 36.2 & 29.0 & 23.8 & 41.7 & 50.4 & 7.8 & 44.9 & 46.7 & 8.3 \\
\hline Chile & 297 & 46.5 & 53.5 & 10.8 & 36.7 & 27.6 & 24.9 & 41.4 & 47.5 & 11.1 & 61.6 & 23.6 & 14.8 \\
\hline Colombia & 339 & 49.9 & 50.1 & 10.0 & 35.7 & 27.4 & 26.8 & 64.0 & 31.0 & 5.0 & 66.4 & 22.1 & 11.5 \\
\hline Costa Rica & 273 & 47.6 & 52.4 & 13.6 & 35.5 & 30.0 & 20.9 & 34.1 & 54.2 & 11.7 & 83.9 & 11.4 & 4.8 \\
\hline Ecuador & 268 & 50.4 & 49.6 & 13.4 & 40.3 & 29.9 & 16.4 & 44.8 & 40.7 & 14.6 & 79.1 & 11.9 & 9.0 \\
\hline Peru & 330 & 48.2 & 51.8 & 14.5 & 39.7 & 24.8 & 20.9 & 47.0 & 30.0 & 23.0 & 20.6 & 67.6 & 11.8 \\
\hline Venezuela & 367 & 49.9 & 50.1 & 13.4 & 42.2 & 27.8 & 16.6 & 80.9 & 14.2 & 4.9 & 69.2 & 13.1 & 17.7 \\
\hline Full sample & 2730 & 47.8 & 52.2 & 12.1 & 37.2 & 28.6 & 22.2 & 51.2 & 38.8 & 10.0 & 60.1 & 29.7 & 10.2 \\
\hline
\end{tabular}


The average time of MVPA was $34.88 \mathrm{~min} /$ day, ranging from 31.16 in Venezuela to 40.27 in Chile. Concerning NC, $37.0 \%$ of the full sample was classified as having elevated NC. Chile was the country with the highest percentage of people with elevated NC with more than half $(56.9 \%)$, and Colombia had the lowest percentage (24.8\%) (Table 3).

Table 3. Descriptive analysis of moderate-to-vigorous physical activity (Mean and SD) and neck circumference (frequency and \%) of adolescents and adults from eight Latin America countries $(n=2730)$.

\begin{tabular}{|c|c|c|c|}
\hline \multirow[b]{2}{*}{ Country } & \multirow{2}{*}{$\begin{array}{c}\text { MVPA } \\
\text { Min/day } \\
\text { Mean (SD) }\end{array}$} & \multicolumn{2}{|c|}{ Neck circumference } \\
\hline & & $\begin{array}{c}\text { Normal } \\
\mathrm{n}(\%)\end{array}$ & $\begin{array}{c}\text { Elevated } \\
\mathrm{n}(\%)\end{array}$ \\
\hline Argentina & $32.81(22.63)$ & $169(57.7 \%)$ & $124(42.3 \%)$ \\
\hline Brazil & $33.37(24.63)$ & $405(71.9 \%)$ & $158(28.1 \%)$ \\
\hline Chile & $40.27(23.66)$ & $128(43.1 \%)$ & 169 (56.9\%) \\
\hline Colombia & $34.84(24.63)$ & $255(75.2 \%)$ & $84(24.8 \%)$ \\
\hline Costa Rica & $32.41(28.19)$ & $149(54.6 \%)$ & $124(45.4 \%)$ \\
\hline Ecuador & $40.04(30.58)$ & $188(70.1 \%)$ & $80(29.9 \%)$ \\
\hline Peru & $36.43(26.60)$ & $212(64.2 \%)$ & $118(35.8 \%)$ \\
\hline Venezuela & $31.16(21.91)$ & $213(58.0 \%)$ & $154(42.0 \%)$ \\
\hline Full sample & $34.88(25.40)$ & $1719(63.0 \%)$ & $1011(37.0 \%)$ \\
\hline
\end{tabular}

MVPA: moderate-to-vigorous physical activity.

Tables 4 and 5 present the results of the multilevel logistic regression analysis describing the association between MVPA and NC. The effect of daily MVPA (min/day) on NC, considering two hierarchical levels (country and region) and adjusted for sex, age, SEL, and educational level, is presented in Table 4. Overall, the increase of one min/day of MVPA is associated with a decrease of $0.6 \%$ in the chance of having an elevated NC $(\mathrm{OR}=0.994, \mathrm{Cl} 95 \%=0.990$ 0.998, $p=0.003)$. The association was similar across all countries but only significant in two: Costa Rica (OR $=0.980$, Cl95\% $=0.964-0.997, p=0.024)$ and Peru (OR $=0.989, \mathrm{Cl} 95 \%=0.980-0.999, p=0.031)($ Table 5$)$. 
Table 4. Multilevel logistic models for moderate-to-vigorous physical activity (min/day) with neck circumference of adolescents and adults from eight Latin America countries-full sample $(\mathrm{n}=$ 2730).

\begin{tabular}{lll}
\hline \multirow{2}{*}{ Independent variables } & \multicolumn{2}{l}{$\begin{array}{l}\text { Dependent variable: } \\
\text { Neck circumference (normal and elevated) }\end{array}$} \\
\cline { 2 - 3 } & $\mathbf{O R}$ (Cl95\%) & $\mathbf{p}$ \\
\hline MVPA (min/day) & $\mathbf{0 . 9 9 4}(\mathbf{0 . 9 9 0 , 0 . 9 9 8 )}$ & $\mathbf{0 . 0 0 3}$ \\
Sex female (vs. male) & $0.739(0.624,0.875)$ & $<0.001$ \\
Age (years) & $1.013(1.007,1.019)$ & $<0.001$ \\
Socioeconomic level medium (vs. low) & $1.143(0.947,1.380)$ & 0.164 \\
Socioeconomic level high (vs. low) & $1.003(0.731,1.378)$ & 0.983 \\
Educational level high school (vs. basic or lower) & $0.756(0.613,0.932)$ & 0.009 \\
Educational level university degree (vs. basic or lower) & $0.780(0.573,1.062)$ & 0.114 \\
\hline
\end{tabular}

Multilevel logistic model with three levels (individual, region, country).

MVPA: moderate-to-vigorous physical activity; OR: odds ratio; C195\%: 95\% confidence interval.

Table 5. Multilevel logistic models for moderate-to-vigorous physical activity (min/day) with neck circumference of adolescents and adults from eight Latin America countries-in each country $(n=$ 2730).

\begin{tabular}{llc}
\hline \multirow{2}{*}{ Countries } & \multicolumn{2}{l}{$\begin{array}{l}\text { Dependent variable: } \\
\text { Neck circumference (normal and elevated) }\end{array}$} \\
\cline { 2 - 3 } MV (Cl95\%) & $\boldsymbol{p}$ \\
\hline Argentina & $0.996(0.984,1.008)$ & 0.490 \\
Brazil & $0.990(0.975,1.006)$ & 0.214 \\
Chile & $0.998(0.982,1.015)$ & 0.846 \\
Colombia & $0.990(0.979,1.002)$ & 0.105 \\
Costa Rica & $0.980(0.964,0.997)$ & $\mathbf{0 . 0 2 4}$ \\
Ecuador & $0.997(0.984,1.010)$ & 0.643 \\
Peru & $0.989(0.980,0.999)$ & $\mathbf{0 . 0 3 1}$ \\
Venezuela & $0.990(0.976,1.004)$ & 0.178 \\
\hline
\end{tabular}

Multilevel logistic models, one for each country, with two levels (individual, region), adjusted for sex, age, socioeconomic level, and educational level.

MVPA: moderate-to-vigorous physical activity; OR: odds ratio; CI95\%: 95\% confidence interval.

\section{Discussion}

This study aimed to investigate the association of accelerometerdetermined MVPA with NC in adolescents and adults from eight LA countries. The average time of MVPA was $34.88 \mathrm{~min} /$ day, and $37.0 \%$ of the full sample was classified as having elevated NC. Overall, the increase of one min/day of MVPA is associated with a decrease of $0.6 \%$ in the chance of having an elevated NC. When analyzed by country, the association was similar across all 
countries but only significant in Costa Rica and Peru. The effect significance of MVPA (min/day) on NC, considering two hierarchical levels (country and region), was adjusted for sex, age, SEL, and education level.

In parallel with demographic and epidemiological changes, the LA region also faces an important and rapid nutritional transition. The characteristics and stages of development in the transition differ among the various countries. However, one point stands out: the marked increase in the prevalence of obesity in the various population subgroups in nearly all of LA and a decline in undernutrition in most countries [44-46]. In LA, nearly a quarter of the population is obese, and the prevalence has increased to a greater magnitude in Mexico, Argentina, and Chile. A recent review estimated that $20-25 \%$ of the children and adolescents (0-18 years) of LA are overweight or obese [47]. Time trends suggest that these figures might rise further, and, by 2030 , up to $81.9 \%$ of the LA and the Caribbean adult population could be either overweight or obese [48]. This is the first study to report NC for a representative sample of LA adolescents and adults from an urban setting; therefore, the only possible comparison was against previous reports that used other anthropometric methods. The prevalence of obesity $\left(\mathrm{BMI} \geq 30 \mathrm{~kg} / \mathrm{m}^{2}\right)$ in São Paulo, Brazil, was $23.6 \%$ and in Santiago, Chile, was $31.1 \%$ [49]. In our study, we found $28.1 \%$ elevated NC in Brazil and $56.7 \%$ in Chile.

The ongoing epidemic of obesity with its multiple related health problems is likely to overstretch the LA public health agenda with its related health problems [50]. Based on the results of 57 prospective studies totaling about 900,000 people, each $5 \mathrm{~kg} / \mathrm{m}^{2}$ higher BMI was associated, on average, with $30 \%$ higher overall mortality. The corresponding increases in mortality due to 
specific causes were $40 \%$ for vascular diseases; $60-120 \%$ for diabetes, kidney, and liver diseases; $10 \%$ for cancer; and $20 \%$ for respiratory diseases and all other causes [51].

Anthropometric measurements showing high sensitivity and specificity in predicting overweight and fat accumulation in the upper body, such as NC, for example, are feasible $[8,9,52]$. NC measurement is simple to perform and inexpensive, has no variation in its magnitude throughout the day, and is preferable in cold weather when individuals are wearing heavy clothing and in some cases, such as obese or morbidly obese, which feature "belly apron" or various waistlines over the abdomen [53-56].

It is important to consider that NC has good intra- and inter-observer reliability and does not require multiple measures for accuracy and reliability, even when compared to WC. Parameters in addition to BMI have long been proposed with the aim of better defining the body composition of an individual [57], particularly with respect to fat accumulation in the central region, which is fully associated with the development of metabolic diseases including the metabolic syndrome, characterized by central obesity, dyslipidemia, hypertension, and insulin resistance. Upper body fat distribution has been considered a risk factor of CVD. It has been reported that free fatty acids are released in larger proportion from upper body subcutaneous fat than lower body subcutaneous fat [58]. Moreover, NC has been used as an index for such an adverse risk profile $[59,60]$.

Joshipura et al. [9] showed that NC was significantly associated with measures of overall and central adiposity; the magnitude of the associations is modest, ranging from 0.45 to 0.66 . The correlations relating both neck and other 
anthropometric measures with metabolic factors are below 0.47 , suggesting modest to weak correlations that are similar or higher for NC (except with hsCRP and fasting glucose). Importantly, compared to traditional anthropometric measures such as BMI, WC, and body fat percent, NC showed higher positive associations with prediabetes and higher inverse association with HDL-C, independent of major confounders [9].

This is the first study reporting significant association of accelerometerdetermined MVPA with NC of nationally representative samples from urban populations from LA countries (Argentina, Brazil, Chile, Colombia, Costa Rica, Ecuador, Peru, and Venezuela). This study supports previous research that has shown negative relationships between accelerometer-determined MVPA and body composition variables $[61,62]$. Our results corroborate those of Van Dyck et al. [62], who reported significant associations of accelerometer-determined MVPA with BMI in adults from 12 countries, independent of country and SEL. Our study showed significant association between MVPA and NC, independent of sex, age, SEL, and educational level. Both our study and the Van Dick et al. [62] study used the cut-point of $\geq 1952$ counts/min for MVPA [28]. Higher levels of physical activity may have important additional beneficial effects on fitness or other health outcomes [63]. However, one must keep in mind that the present results are cross-sectional; therefore, no true dose-response relationships can be assumed.

As shown in Table 4, countries achieved high physical activity in different ways with six of the most active countries (Costa Rica, Colombia, Perú, Argentina, Brazil, and Venezuela) showing a greater volume of vigorousintensity physical activity relative to moderate-intensity activity and walking. 
Four of the countries with substantial rates of high physical activity had more than $44 \%$ of overall physical activity derived from walking (Costa Rica, Perú, Brazil, and Venezuela), suggesting that one can achieve high levels of physical activity with lesser contribution from vigorous activity. One conclusion from these results is that different patterns of physical activity are associated with high prevalence estimates, so countries could tailor physical activity promotion strategies to local infrastructure, available programs, and culture.

Table 5 presents the results of the multi-level logistic regression analysis describing the significant association between MVPA and NC for Costa Rica $(\mathrm{OR}=0.980, \mathrm{Cl} 95 \%=0.964-0.997)$ and Peru $(\mathrm{OR}=0.989, \mathrm{Cl} 95 \%=0.980-$ 0.999), considering two hierarchical levels (country and region) and adjusted for sex, age, SEL, and educational level. One conclusion from these results is that different patterns of MVPA are associated with high prevalence estimates of elevated NC, so countries could tailor physical activity and obesity promotion strategies to local infrastructure, available programs, and culture. Overall, these results highlight the complexity and diversity of each country's local context and, thus, the need to better understand these realities when defining evidencebased interventions to improve nutrition in the region $[64,65]$. For example, Peruvian people have increased their BMI in $1.3 \mathrm{~kg} / \mathrm{m}^{2}$ between 1996 and 2011 (with a rate of $0.09 \mathrm{~kg} / \mathrm{m}^{2}$ per year), surpassing-and almost doubling-the global female trend rate reported by Finucane et al. [66] but supporting the fact that LA countries are facing a rapid nutritional transition. Worldwide, adult BMI has increased by $0.4 \mathrm{~kg} / \mathrm{m}^{2}$ and $0.5 \mathrm{~kg} / \mathrm{m}^{2}$ per decade in male and female participants, respectively, from 1980 to 2008 with LA presenting the second highest BMI rise after Oceania [66]. Moreover, adult global age-standardized 
obesity and overweight levels have been augmented from $6.4 \%$ to $12.0 \%$ and from $24.6 \%$ to $34.4 \%$, respectively [67]. In addition, sedentary lifestyles and physical inactivity due to rapid urbanization have been contributing to escalating levels of over-nutrition [45]. In a region experiencing escalating rates of obesity and inactivity among urban populations in particular, there is an opportunity to promote effective interventions to increase physical activity and prevent noncommunicable diseases.

The results of the study may not be directly generalizable to other countries. Nevertheless, no study has evaluated the accelerometer-determined MVPA and NC of adolescent and adult populations in LA using a standardized methodology across a consortium of several participating countries. The present study had several strengths: the large sample size; comparable data collection protocols across eight countries; use of objective methods to assess physical activity, techniques, and approaches that are rare in LA countries, where most previous research has used questionnaires indirect measures of physical activity $[68,69]$; and it expands the existing literature by reporting the association of physical activity with NC. However, some limitations must be acknowledged. First, the ELANS employed a cross-sectional design, precluding inferences about causality. Second, obtained estimates of MVPA may not be representative of the total population in the participating countries since participants were recruited based on geographical location (only urban areas), gender, age, and SEL. Third, only physical activity was examined in relation to weight outcomes; a more complete perspective could have been provided if diet-related measures, information on sleep duration, and a more precise measure of body fat were included as well. 


\section{Conclusions}

When analyzing all countries together, the present study provided evidence of significant associations between MVPA and NC in adolescents and adults from LA, independent of sex, age, SEL, and educational level. When analyzed separately by country, only Costa Rica and Peru showed significant association between MVPA and NC.

This analysis of accelerometry data and NC represents the first examination of these associations in eight LA countries. Further research is needed to continue to develop means of gathering more comprehensive data to better elucidate the full nature of the correlates of obesity and to understand the differences between countries in the observed associations.

\section{Competing interests}

All authors declare that they have no competing interests.

\section{Acknowledgments}

We would like to thank the following individuals at each of the participating sites who made substantial contributions to the ELANS: Luis A. Moreno, Beate Lloyd, Brenda Lynch, Mariela Jauregui, Alejandra Guidi, Luis Costa, and Regina Mara Fisberg.

¥The following are members of ELANS Study Group: Chairs: Mauro Fisberg and Irina Kovalskys; Co-chair: Georgina Gómez Salas; Core Group members: Attilio Rigotti, Lilia Yadira Cortés Sanabria, Georgina Gómez Salas, Martha Cecilia Yépez García, Rossina Gabriella Pareja Torres, and Marianella Herrera-Cuenca; Steering Committee: Berthold Koletzko, Luis A. Moreno, 
Michael Pratt, and Katherine L. Tucker; Project Managers: Viviana Guajardo and Ioná Zalcman Zimberg; International Life Sciences Institute-Argentina: Irina Kovalskys, Viviana Guajardo, María Paz Amigo, Ximena Janezic, and Fernando Cardini; Universidad I Salud: Myriam Echeverry and Martin Langsman; Instituto Pensi-Hospital Infantil Sabara-Brazil: Mauro Fisberg, Ioná Zalcman Zimberg, and Natasha Aparecida Grande de França; Pontificia Universidad Católica de Chile: Attilio Rigotti, Guadalupe Echeverría, Leslie Landaeta, and Óscar Castillo; Pontificia Universidad Javeriana-Colombia: Lilia Yadira Cortés Sanabria, Luz Nayibe Vargas, Luisa Fernanda Tobar, and Yuri Milena Castillo; Universidad de Costa Rica: Georgina Gómez Salas, Rafael Monge Rojas, and Anne Chinnock; Universidad San Francisco de Quito-Ecuador: Martha Cecilia Yépez García, María Elisa Herrera Fontana, Mónica Villar Cáceres, and María Belén Ocampo; Instituto de Investigación Nutricional-Perú: Rossina Pareja Torres, María Reyna Liria, Krysty Meza, Mellisa Abad, and Mary Penny; Universidad Central de Venezuela: Marianella Herrera-Cuenca, Maritza Landaeta, Betty Méndez, Maura Vasquez, Omaira Rivas, Carmen Meza, Servando Ruiz, Guillermo Ramirez, and Pablo Hernández; Statistical advisor: Alexandre D.P. Chiavegatto Filho; Accelerometry analysis: Priscila Bezerra Gonçalves and Claudia Alberico; Physical activity advisor: Gerson Luis de Moraes Ferrari.

\section{Funding source}

The ELANS was supported by a scientific grant from the Coca Cola Company and support from the Ferrero, Instituto Pensi/Hospital Infantil Sabara, 
International Life Science Institute of Argentina, Universidad de Costa Rica, Pontificia Universidad Católica de Chile, Pontificia Universidad Javeriana, Universidad Central de Venezuela/Fundación Bengoa, Universidad San Francisco de Quito, and Instituto de Investigación Nutricional de Peru. The founding sponsors had no role in study design; data collection, analyses, or interpretation; writing of the manuscript; or the decision to publish the results. This study is registered at www.clinicaltrials.gov (No. NCT02226627).

\section{Authors' contributions}

G.L.M.F. conceived, designed, and helped to write and revise the manuscript; I.K. was responsible for coordinating the study and contributed to the intellectual content; M.F. was responsible for coordinating the study and contributed to the intellectual content and helped to write and revise the manuscript; G.G.S. interpreted the data, helped to write and revise the manuscript, and helped implement the study; A.R. interpreted the data, helped to write and revise the manuscript, and helped implement the study; L.Y.C.S. interpreted the data, helped to write and revise the manuscript, and helped implement the study; M.C.Y.G. interpreted the data, revised the manuscript, and helped implement the study; R.G.P.T. interpreted the data, helped to write and revise the manuscript, and helped implement the study; M.H-C. interpreted the data, revised the manuscript, and helped implement the study; I.Z.Z. was responsible for coordinating the study, interpreted the data, and revised the manuscript; V.G. interpreted the data, revised the manuscript, and helped implement the study; M.P. interpreted the data, revised the manuscript, and helped implement the study; C.P. interpreted the data and helped to write and revise the 
manuscript; D.S. interpreted the data and helped to write and revise the manuscript. All authors contributed to the study design, critically reviewed the manuscript, and approved the final version. All authors contributed to the study design, critically reviewed the manuscript, and approved the final version.

\section{References}

1. Wang, Y.C.; McPherson, K.; Marsh, T.; Gortmaker, S.L.; Brown, M. Health and economic burden of the projected obesity trends in the USA and the UK. Lancet. 2011,378, 9793, 815-825. DOI: 10.1016/S0140-6736(11)6081460813. Avaliable online: https://www.ncbi.nlm.nih.gov/pubmed/21872750 (Accessed on 26 June 2018).

2. Gupta, N.; Goel, K.; Shah, P.; Misra, A. Childhood obesity in developing countries: epidemiology, determinants, and prevention. Endocr. Rev. 2012, 33, 1, 48-70. DOI: 10.1210/er.2010-0028. Avaliable online: https://www.ncbi.nlm.nih.gov/pubmed/22240243 (Accessed on 26 June 2018).

3. Klop, B.; Elte, J.W.; Cabezas, M.C. Dyslipidemia in obesity: mechanisms and potential targets. Nutrients. 2013, 5, 4, 1218-1240. DOI: 10.3390/nu5041218. Avaliable online: https://www.ncbi.nlm.nih.gov/pubmed/23584084 (Accessed on 26 June 2018). 4. Leggio, M.; Lombardi, M.; Caldarone, E.; Severi, P.; D'Emidio, S.; Armeni, M.; Bravi, V.; Bendini, M.G.; Mazza, A. The relationship between obesity and hypertension: an updated comprehensive overview on vicious twins. Hypertens. Res. 2017, 40, 12, 947-963. DOI: 10.1038/hr.2017.75. Avaliable online: https://www.ncbi.nlm.nih.gov/pubmed/?term=The+relationship+between+obesit 
$\mathrm{y}+$ and+hypertension $\% 3 \mathrm{~A}+\mathrm{an+updated+comprehensive+overview+on+vicious+t}$ wins (Accessed on 26 June 2018).

5. Umer, A.; Kelley, G.A.; Cottrell, L.E.; Giacobbi, P. Jr.; Innes, K.E.; Lilly,

C.L. Childhood obesity and adult cardiovascular disease risk factors: a systematic review with meta-analysis. BMC Public Health. 2017, 17, 1, 683. DOI: 10.1186/s12889-017-4691-z. DOI: 10.1186/s12889-017-4691-z. Avaliable online: https://www.ncbi.nIm.nih.gov/pubmed/28851330 (Accessed on 26 June 2018).

6. Li, Y.; Pan, A.; Wang, D.D.; Liu, X.; Dhana, K.; Franco, O.H.; Kaptoge, S.; Di Angelantonio, E.; Stampfer, M., Willett, W.C.; et al. Impact of healthy lifestyle factors on life expectancies in the US population. Circulation. 2018, DOI: 10.1161/CIRCULATIONAHA.117.032047. Avaliable online: https://www.ncbi.nlm.nih.gov/pubmed/?term=Impact+of+healthy+lifestyle+factor s+on+life+expectancies+in+the+US+population (Accessed on 26 June 2018).

7. Fox, C.S.; Massaro, J.M.; Hoffmann, U.; Pou, K.M.; Maurovich-Horvat, P.; Liu, C.Y.; Vasan, R.S.; Murabito, J.M.; Meigs J.B.; Cupples, L.A.; et al. Abdominal visceral and subcutaneous adipose tissue compartments: association with metabolic risk factors in the Framingham Heart Study. Circulation. 2007,116, 1, 39-48. DOI: 10.1161/CIRCULATIONAHA.106.675355. Avaliable online: https://www.ncbi.nlm.nih.gov/pubmed/?term=Abdominal+visceral+and+subcuta neous+adipose+tissue+compartments $\% 3 A+a s s o c i a t i o n+w i t h+m e t a b o l i c+r i s k+f a$ ctors+in+the+Framingham+Heart+Study.+Circulation (Accessed on 26 June 2018). 
8. Ferretti Rde, L.; Cintra Ide, P.; Passos, M.A; de Moraes Ferrari, G.L.; Fisberg, M. Elevated neck circumference and associated factors in adolescents. BMC Public Health. 2015, 15, 208. DOI: 10.1186/s12889-015-1517-8. Avaliable online: https://www.ncbi.nlm.nih.gov/pubmed/25880196 (Accessed on 26 June 2018).

9. Joshipura, K.; Munoz-Torres, F.; Vergara, J.; Palacios, C.; Perez, C.M. Neck circumference may be a better alternative to standard anthropometric measures. J. Diabetes Res. 2016, 2016, 6058916. DOI: $10.1155 / 2016 / 6058916$.

Avaliable online: https://www.ncbi.nlm.nih.gov/pubmed/?term=Neck+circumference+may+be+a+ better+alternative+to+standard+anthropometric+measures (Accessed on 26 June 2018).

10. Baena, C.P.; Lotufo, P.A.; Fonseca, M.G.; Santos, I.S.; Goulart, A.C.; Bensenor, I.M. Neck circumference is independently associated with cardiometabolic risk factors: cross-sectional analysis from ELSA-Brasil. Metab. Syndr. Relat. Disord. 2016, 14, 3, 145-153. DOI: 10.1089/met.2015.0083. Avaliable online: https://www.ncbi.nlm.nih.gov/pubmed/?term=Neck+circumference+is+independ ently+associated+with+cardiometabolic+risk+factors $\% 3 A+$ crosssectional+analysis+from+ELSA-Brasil. (Accessed on 26 June 2018).

11. Dai, Y.; Wan, X.; Li, X.; Jin, E.; Li, X. Neck circumference and future cardiovascular events in a high-risk population--A prospective cohort study. Lipids Health Dis. 2016, 15, 46. DOI: 10.1186/s12944-016-0218-3. Avaliable online: 
https://www.ncbi.nlm.nih.gov/pubmed/?term=Neck+circumference+and+future+ cardiovascular+events+in+a+high-risk+population--A+prospective+cohort+study (Accessed on 26 June 2018).

12. Morais, A.A.; Morais, U.A.B.; Soares, M.M.S.; Romano, M.C.C.; Lamounier, J.A. Neck circumference in adolescents and cardiometabolic risk: A sistematic review. Rev. Assoc. Med. Bras (1992), 2018, 64, 1, 54-62. DOI: 10.1590/1806-9282.64.01.54.

Avaliable online: https://www.ncbi.nlm.nih.gov/pubmed/?term=Neck+circumference+in+adolesce nts+and+cardiometabolic+risk\%3A+A+sistematic+review (Accessed on 26 June 2018).

13. Kanejima, Y.; Kitamura, M.; Izawa, K.P. Self-monitoring to increase physical activity in patients with cardiovascular disease: a systematic review and meta-analysis. Aging Clin. Exp. Res. 2018. DOI: 10.1007/s40520-0180960-7. Avaliable online: https://www.ncbi.nlm.nih.gov/pubmed/29714027 (Accessed on 26 June 2018).

14. Matthews, C.E.; Keadle, S.K.; Troiano, R.P.; Kahle, L.; Koster, A.; Brychta, R.; Van Domelen, D.; Caserotti, P.; et al. Accelerometer-measured dose-response for physical activity, sedentary time, and mortality in US adults. Am. J. Clin. Nutr. 2016, 104, 5, 1424-1432. DOI: 10.3945/ajcn.116.135129. Avaliable online: https://www.ncbi.nlm.nih.gov/pubmed/?term=Accelerometermeasured+doseresponse+for+physical+activity $\% 2 \mathrm{C}+$ sedentary+time $\% 2 \mathrm{C}+$ and +mortality+in+U S+adults (Accessed on 26 June 2018).

15. Hallal, P.C.; Andersen, L.B.; Bull, F.C.; Guthold, R.; Haskell, W.; Ekelund, U.; Lancet Physical Activity Series Working Group. Global physical 
activity levels: surveillance progress, pitfalls, and prospects. Lancet. 2012, 380, 9838, 247-257. DOI: 10.1016/S0140-6736(12)60646-1. Avaliable online: https://www.ncbi.nlm.nih.gov/pubmed/?term=Lancet+Physical+Activity+Series+ Working+Group.+Global+physical+activity+levels\%3A+surveillance+progress $\%$ 2C+pitfalls\%2C+and+prospects (Accessed on 26 June 2018).

16. Institute for Health Metrics and Evaluation. 2013. Available at: www.healthmetricsandevaluation.org/gbd/visualizations/gbd-arrow-diagram. (Accessed on 22 June 2018).

17. United Nations. World urbanization prospects: the 2011 revision, data tables and highlights. New York; 2013.

18. Barreto, S.M.; Miranda, J.J.; Figueroa, J.P.; Schmidt, M.I.; Munoz, S.; Kuri-Morales, P.P.; Silva, J.B. Jr. Epidemiology in Latin America and the Caribbean: current situation and challenges. Int. J. Epidemiol. 2012, 41, 2, 557571. DOI: 10.1093/ije/dys017. Avaliable online: https://www.ncbi.nlm.nih.gov/pubmed/22407860 (Accessed on 26 June 2018). 19. Hoehner, C.M.; Soares, J.; Parra Perez, D.; Ribeiro, I.C.; Joshu, C.E.; Pratt, M,; Legetic, B.D.; Malta, D.C.; Matsudo, V.R,; Ramos, L.R.; et al. Physical activity interventions in Latin America: a systematic review. Am. J. Prev. Med. 2008, 34, 3, 224-233. DOI: 10.1016/j.amepre.2007.11.016. Avaliable online: https://www.ncbi.nlm.nih.gov/pubmed/18312811 (Accessed on 26 June 2018).

20. Corvalan, C.; Garmendia, M.L.; Jones-Smith, J.; Lutter, C.K.; Miranda, J.J.; Pedraza, L.S.; Popkin, B.M.; Ramirez-Zea, M.; Salvo, D.; Stein, A.D. Nutrition status of children in Latin America. Obes. Rev. 2017, 18 Suppl 2, 7-18. DOI: 10.1111/obr.12571.

Avaliable

online: 
https://www.ncbi.nlm.nih.gov/pubmed/?term=Nutrition+status+of+children+in+L atin+America.+Obes.+Rev.+2017 (Accessed on 26 June 2018).

21. Jefferis, B.J.; Parsons, T.J.; Sartini, C.; Ash, S.; Lennon, L.T.; Wannamethee, S.G.; Lee, I.M.; Whincup, P.H. Does duration of physical activity bouts matter for adiposity and metabolic syndrome? A cross-sectional study of older British men. Int. J. Behav. Nutr. Phys. Act. 2016, 13, 36. DOI: 10.1186/s12966-016-0361-2.

Avaliable online: https://ijbnpa.biomedcentral.com/articles/10.1186/s12966-016-0361-2 (Accessed on 26 June 2018).

22. Salvo, D.; Reis, R.S.; Sarmiento, O.L.; Pratt, M. Overcoming the challenges of conducting physical activity and built environment research in Latin America: IPEN Latin America. Prev. Med. 2014, 69 Suppl 1, S86-92. DOI: 10.1016/j.ypmed.2014.10.014. Avaliable

online: https://linkinghub.elsevier.com/retrieve/pii/S0091-7435(14)00378-8 (Accessed on 26 June 2018).

23. Ferrari, G.L.; Oliveira, L.C.; Araujo, T;L.; Matsudo, V.; Barreira, T.V.; Tudor-Locke, C.; Katzmarzyk, P. Moderate-to-vigorous physical activity and sedentary behavior: independent associations with body composition variables in Brazilian children. Pediatr. Exerc. Sci. 2015, 27, 3, 380-389. DOI: 10.1123/pes.2014-0150. Avaliable online: https://www.ncbi.nlm.nih.gov/pubmed/?term=Moderate-tovigorous+physical+activity+and+sedentary+behavior\%3A+independent+associ ations+with+body+composition+variables+in+Brazilian+children (Accessed on 26 June 2018). 
24. Fisberg, M.; Kovalskys, I.; Gomez, G.; Rigotti, A.; Cortes, L.Y.; HerreraCuenca, M.; Yépez, M.C.; Pareja, R.G.; Guajardo, V.; Zimberg, I.Z.; et al. Latin American Study of Nutrition and Health (ELANS): rationale and study design. BMC Public Health. 2016, 16, 1, 93. DOI: 10.1186/s12889-016-2765-y. Avaliable online: https://www.ncbi.nlm.nih.gov/pubmed/?term=.+Latin+American+Study+of+Nutrit ion+and+Health+(ELANS)\%3A+rationale+and+study+design (Accessed on 26 June 2018).

25. Colley, R.; Connor Gorber, S.; Tremblay, M.S. Quality control and data reduction procedures for accelerometry-derived measures of physical activity. Health Rep. 2010, 21, 1, 63-69. Avaliable online: http://www.statcan.gc.ca/pub/82-003-x/2010001/article/11066-eng.pdf (Accessed on 26 June 2018).

26. Trost, S.G.; Loprinzi, P.D.; Moore, R.; Pfeiffer, K.A. Comparison of accelerometer cut points for predicting activity intensity in youth. Med. Sci. Sports Exerc. 2011, 43, 7, 1360-1368. DOI: 10.1249/MSS.0b013e318206476e. Avaliable online: https://www.ncbi.nlm.nih.gov/pubmed/?term=Comparison+of+accelerometer+cu $\mathrm{t}+$ points+for+predicting+activity+intensity+in+youth (Accessed on 26 June 2018).

27. Salvo, D.; Sarmiento, O.L.; Reis, R.S.; Hino, A.A.F.; Bolivar, M.A.; Lemoine, P.D.; Gonçalves, P.B.; Pratt, M. Where Latin Americans are physically active, and why does it matter? Findings from the IPEN-adult study in Bogota, Colombia; Cuernavaca, Mexico; and Curitiba, Brazil. Prev. Med. 2017, 103S, S27-S33. DOI: 10.1016/j.ypmed.2016.09.007. Avaliable online: 
https://www.ncbi.nlm.nih.gov/pubmed/?term=Where+Latin+Americans+are+phy sically+active $\% 2 \mathrm{C}+$ and+why+does+it+matter\%3F+Findings+from+the+IPENadult+study+in+Bogota (Accessed on 26 June 2018).

28. Freedson, P.S.; Melanson, E.; Sirard, J. Calibration of the computer science and applications, inc. accelerometer. Med. Sci. Sports Exerc. 1998, 30, 5, 777-781.

29. Freedson, P.S.; Miller, K. Objective monitoring of physical activity using motion sensors and heart rate. Res. Q. Exerc. Sport. 2000, 71, Suppl 2, S2129.

30. Freedson, P.S.; Lyden, K.; Kozey-Keadle, S.; Staudenmayer, J. Evaluation of artificial neural network algorithms for predicting METs and activity type from accelerometer data: validation on an independent sample. J. Appl Physiol. 2011, 111, 6, 1804-1812. DOI: 10.1152/japplphysiol.00309.2011. Avaliable online: https://www.ncbi.nlm.nih.gov/pubmed/?term=Evaluation+of+artificial+neural+net work+algorithms+for+predicting+METs+and+activity+type+from+accelerometer +data\%3A+validation+on+an+independent+sample (Accessed on 26 June 2018).

31. Sasaki, J.E.; John, D.; Freedson, P.S. Validation and comparison of ActiGraph activity monitors. J. Sci. Med. Sport. 2011, 14, 5, 411-416. DOI: 10.1016/j.jsams.2011.04.003. Avaliable online: https://www.ncbi.nlm.nih.gov/pubmed/21616714 (Accessed on 26 June 2018).

32. Cornier, M.A.; Despres, J.P.; Davis, N.; Grossniklaus, D.A.; Klein, S.; Lamarche, B.; Lopez-Jimenez, F.; Rao, G.; St-Onge, M.P.; Towfighi, A.; et al. Assessing adiposity: a scientific statement from the American Heart 
Association. Circulation. 2011, 124, 18, 1996-2019. DOI: 10.1161/CIR.0b013e318233bc6a. Avaliable online: https://www.ncbi.nlm.nih.gov/pubmed/?term=Assessing+adiposity\%3A+a+scien tific+statement+from+the+American+Heart+Association.+Circulation (Accessed on 26 June 2018).

33. Onat, A.; Hergenc, G.; Yuksel, H.; Can, G.; Ayhan, E.; Kaya, Z.; Dursunoğlu, D. Neck circumference as a measure of central obesity: associations with metabolic syndrome and obstructive sleep apnea syndrome beyond waist circumference. Clin. Nutr. 2009, 28, 1, 46-51. DOI: 10.1016/j.clnu.2008.10.006. Avaliable online: https://www.ncbi.nlm.nih.gov/pubmed/?term=Neck+circumference+as+a+meas ure+of+central+obesity\%3A+associations+with+metabolic+syndrome+and+obst ructive+sleep+apnea+syndrome+beyond+waist+circumference (Accessed on 26 June 2018).

34. Pesquisa de Orçamentos Familiares (POF) 2008-2009: Antropometria e estado nutricional de crianças, adolescentes e adultos no Brasil. Rio de Janeiro: Instituto Brasileiro de Geografia e Estatística. 2010.

35. Instituto Nacional de Estadística. República Bolivariana de Venezuela, síntesis estadística de pobreza e indicadores de desigualdad. 2011.

36. Asociacion Investigadores de Mercado. Grupos socioeconómicos Chile. Chile: Asociacion investigadores de mercado; 2012.

37. IPSOS. Estudio general de medios. 2012.

38. Instituto Nacional de Estadística y Censos de Ecuador. Encuesta de estratificación de nivel socioeconómico. 2011. 
39. Departamento Administrativo Nacional de Estadisticas de Colombia. Proyecciones nacionales y departamentales de poblacion 2005-2020, Estudios Postcensales No. 7. 2009.

40. Comisión de Enlace Institucional AAM-SAIMO-CEIM. Nivel Socioeconómico. Antecedentes, marco conceptual, enfoque metodológico y fortalezas. Buenos Aires: Comisión de Enlace Institucional AAM-SAIMO-CEIM; 2006.

41. Associação Brasileira de Empresas de Pesquisa (ABEP). Critério padrão de classificação econômica Brasil. 2013.

42. R Core Team. R: A language and environment for statistical computing. $R$ foundation for statistical computing, Vienna, Austria. URL https://www.Rproject.org/. 2017. (Accessed on 25 June 2018).

43. Bates, D.; Maechler, M.; Bolker, B.; Walker, S. Fitting linear mixed-effects models using Ime4. J. Stat. Softw. 2015, 67, 1, 1-48. DOI: 10.18637/jss.v067.i01.

44. Filozof, C.; Gonzalez, C.; Sereday, M.; Mazza, C.; Braguinsky, J. Obesity prevalence and trends in Latin-American countries. Obes. Rev. 2001, 2, 2, 99106. DOI: 10.1046/j.1467-789x.2001.00029.x. Avaliable online: https://www.ncbi.nlm.nih.gov/pubmed/?term=Obesity+prevalence+and+trends+i n+Latin-American+countries.+Obes.+Rev (Accessed on 26 June 2018).

45. Uauy, R.; Albala, C.; Kain, J. Obesity trends in Latin America: transiting from under- to overweight. J. Nutr. 2001, 131, 3, 893S-9S. DOI: 10.1093/jn/131.3.893S. Avaliable online: https://www.ncbi.nlm.nih.gov/pubmed/?term=Obesity+trends+in+Latin+America 
$\% 3 \mathrm{~A}+$ transiting+from+under-+to+overweight.+J.+Nutr. (Accessed on 26 June 2018).

46. Bautista, L.E.; Casas, J.P.; Herrera, V.M.; Miranda, J.J.; Perel, P.; Pichardo, R.; González, A.; Sanchez, J.R.; Ferreccio, C.; Aguilera, X.; et al. The Latin American Consortium of Studies in Obesity (LASO). Obes Rev. 2009, 10, 3, 364-70. DOI: 10.1111/j.1467-789X.2009.00591.x. Avaliable online: https://www.ncbi.nlm.nih.gov/pubmed/?term=The+Latin+American+Consortium +of+Studies+in+Obesity+(LASO).+Obes+Rev (Accessed on 26 June 2018).

47. Rivera, J.A.; de Cossio, T.G.; Pedraza, L.S.; Aburto, T.C.; Sanchez, T.G.; Martorell, R. Childhood and adolescent overweight and obesity in Latin America: a systematic review. Lancet Diabetes Endocrinol. 2014, 2, 4, 321-32. DOI: $\quad$ 10.1016/S2213-8587(13)70173-6. Avaliable online: https://www.ncbi.nlm.nih.gov/pubmed/?term=Childhood+and+adolescent+overw eight+and+obesity+in+Latin+America\%3A+a+systematic+review.+Lancet+Diab etes+Endocrinol. (Accessed on 26 June 2018).

48. Kelly, T.; Yang, W.; Chen, C.S.; Reynolds, K.; He, J. Global burden of obesity in 2005 and projections to 2030. Int. J. Obes. (Lond). 2008, 32, 9, 14311437. DOI: 10.1038/ijo.2008.102. Avaliable online: https://www.ncbi.nlm.nih.gov/pubmed/?term=Global+burden+of+obesity+in+200 5+and+projections+to+2030.+Int.+J.+Obes (Accessed on 26 June 2018).

49. Al Snih, S.; Graham, J.E.; Kuo, Y.F.; Goodwin, J.S.; Markides, K.S.; Ottenbacher, K.J. Obesity and disability: relation among older adults living in Latin America and the Caribbean. Am. J. Epidemiol. 2010, 171, 12, 1282-1288. DOI: 10.1093/aje/kwq087. Avaliable online: (Accessed on 26 June 2018). 
50. Schmidt, M.I.; Duncan, B.B.; Azevedo e Silva, G.; Menezes, A.M.; Monteiro, C.A.; Barreto, S.M.; Chor, D.; Menezes, P.R. Chronic noncommunicable diseases in Brazil: burden and current challenges. Lancet. 2011; 377, 9781, 1949-1961. DOI: 10.1016/S0140-6736(11)60135-9. Avaliable online: https://www.ncbi.nlm.nih.gov/pubmed/?term=Chronic+noncommunicable+diseases+in+Brazil\%3A+burden+and+current+challenges (Accessed on 26 June 2018).

51. Prospective Studie Collaboration; Whitlock, G.; Lewington, S.; Sherliker, P.; Clarke, R.; Emberson, J.; Halsey, J.; Qizilbash, N.; Collins, R.; Peto, R. Body-mass index and cause-specific mortality in 900000 adults: collaborative analyses of 57 prospective studies. Lancet. 2009, 373, 9669, 1083-1096. DOI: 10.1016/S0140-6736(09)60318-4.

Avaliable online: https://www.ncbi.nlm.nih.gov/pubmed/?term=Body-mass+index+and+causespecific + mortality + in $+900+000+$ adults $\% 3 A+$ collaborative + analyses $+o f+57+$ pros pective+studies (Accessed on 26 June 2018).

52. Qureshi, N.K.; Hossain, T.; Hassan, M.I.; Akter, N.; Rahman, M.M.; Sultana, M.M.; Ashrafuzzaman, S.M.; Latif, Z.A. Neck circumference as a marker of overweight and obesity and cutoff values for bangladeshi adults. Indian J. Endocrinol. Metab. 2017, 21, 6, 803-808. DOI: 10.4103/ijem.IJEM_196_17.

Avaliable online: https://www.ncbi.nlm.nih.gov/pubmed/?term=Neck+circumference+as+a+marke r+of+overweight+and+obesity+and+cutoff+values+for+bangladeshi+adults.+Indi an+J. (Accessed on 26 June 2018). 
53. Aggarwal, T.; Bhatia, R.C.; Singh, D.; Sobti, P.C. Prevalence of obesity and overweight in affluent adolescents from Ludhiana, Punjab. Indian. Pediatr. $2008,45,6,500-502$.

54. Mason, C.; Katzmarzyk, P.T. Variability in waist circumference measurements according to anatomic measurement site. Obesity. 2009, 17, 9, 1789-1795. DOI: 10.1038/oby.2009.87. Avaliable online: https://www.ncbi.nlm.nih.gov/pubmed/?term=Variability+in+waist+circumference +measurements+according+to+anatomic+measurement+site (Accessed on 26 June 2018).

55. Pereira, P.F.; Serrano, H.M.; Carvalho, G.Q.; Lamounier, J.A.; Peluzio Mdo, C.; Franceschini Sdo C, Priore, S.E. Waist circumference as indicator of body fat and metabolic alterations in teenagers: comparison among four references. Rev. Assoc. Med. Bras. (1992). 2010, 56, 6, 665-669. DOI: 10.1590/S0104-42302010000600014. Avaliable online: https://www.ncbi.nlm.nih.gov/pubmed/?term=Waist+circumference+as+indicator +of+body+fat+and+metabolic+alterations+in+teenagers $\% 3 \mathrm{~A}+$ comparison+amo ng+four+references (Accessed on 26 June 2018).

56. Nafiu, O.O.; Burke, C.; Lee, J.; Voepel-Lewis, T.; Malviya, S.; Tremper, K,K. Neck circumference as a screening measure for identifying children with high body mass index. Pediatrics. 2010, 126, 2, e306-10. DOI: 10.1542/peds.2010-0242. Avaliable online: https://www.ncbi.nlm.nih.gov/pubmed/?term=Neck+circumference+as+a+scree ning+measure+for+identifying+children+with+high+body+mass+index (Accessed on 26 June 2018). 
57. Vasques, A.C.; Rosado, L.; Rosado, G.; Ribeiro Rde, C.; Franceschini, S.; Geloneze, B. Anthropometric indicators of insulin resistance. Arq. Bras. Cardiol. 2010, 95, $1, \quad$ e14-23. DOI: 10.1590/S0066782X2010001100025. Avaliable online: https://www.ncbi.nlm.nih.gov/pubmed/20694396 (Accessed on 26 June 2018). 58. Jensen, M.D. Lipolysis: contribution from regional fat. Annu Rev. Nutr. 1997, 17, 127-139. DOI: 10.1146/annurev.nutr.17.1.127. Avaliable online: https://www.ncbi.nlm.nih.gov/pubmed/?term=Lipolysis\%3A+contribution+from $+r$ egional+fat.+Annu+Rev.+Nutr.+1997\%2C (Accessed on 26 June 2018).

59. Sjostrom, C.D.; Lissner, L.; Sjostrom, L. Relationships between changes in body composition and changes in cardiovascular risk factors: The SOS Intervention Study. Swedish obese subjects. Obes. Res. 1997, 5, 6, 519-30. DOI: 10.1002/j.1550-8528.1997.tb00572.x Avaliable online: https://www.ncbi.nlm.nih.gov/pubmed/?term=Relationships+between+changes+ in+body+composition+and+changes+in+cardiovascular+risk+factors $\% 3 \mathrm{~A}+$ The+ SOS+Intervention+Study (Accessed on 26 June 2018).

60. Sjostrom, C.D.; Hakangard, A.C.; Lissner, L.; Sjostrom, L. Body compartment and subcutaneous adipose tissue distribution--risk factor patterns in obese subjects. Obes. Res. 1995, 3, 1, 9-22. DOI: 10.1002/j.15508528.1995.tb00116.x. Avaliable online: https://www.ncbi.nlm.nih.gov/pubmed/?term=Body+compartment+and+subcuta neous+adipose+tissue+distribution--risk+factor+patterns+in+obese+subjects (Accessed on 26 June 2018).

61. Ramirez, V.; Shokri-Kojori, E.; Cabrera, E.A.; Wiers, C.E.; Merikangas, K.; Tomasi, D.; Wang, G.J.; Volkow, N.D. Physical activity measured with wrist 
and ankle accelerometers: Age, gender, and BMI effects. PloS one. 2018, 13, 4, e0195996. DOI: 10.1371/journal.pone.0195996. Avaliable online: https://www.ncbi.nlm.nih.gov/pubmed/?term=Physical+activity+measured+with+ wrist+and+ankle+accelerometers $\% 3 \mathrm{~A}+\mathrm{Age} \% 2 \mathrm{C}+$ gender $\% 2 \mathrm{C}+$ and $+\mathrm{BMI}+$ effects (Accessed on 26 June 2018).

62. Van Dyck, D.; Cerin, E.; De Bourdeaudhuij, I.; Hinckson, E.; Reis, R.S.; Davey, R.; Sarmiento, O.L.; Mitas, J.; Troelsen, J.; MacFarlane, D.; et al. International study of objectively measured physical activity and sedentary time with body mass index and obesity: IPEN adult study. Int. J. Obes. (Lond). 2015, 39, 2, 199-207. DOI: 10.1038/ijo.2014.115. Avaliable online: https://www.ncbi.nlm.nih.gov/pubmed/?term=International+study+of+objectively +measured+physical+activity+and+sedentary+time+with+body+mass+index+an d+obesity\%3A+IPEN+adult+study (Accessed on 26 June 2018).

63. Donnelly, J.E.; Hillman, C.H.; Castelli, D.; Etnier, J.L.; Lee, S.; Tomporowski, P.; Lambourne, K.; Szabo-Reed, A.N. Physical activity, fitness, cognitive function, and academic achievement in children: a systematic review. Med. Sci. Sports Exerc. 2016, 48, 6, 1223-1224. DOI: 10.1249/MSS.0000000000000966. Avaliable online: https://www.ncbi.nlm.nih.gov/pubmed/27182986 (Accessed on 26 June 2018). 64. Urke, H.B.; Mittelmark, M.B.; Valdivia, M. Trends in stunting and overweight in Peruvian pre-schoolers from 1991 to 2011: findings from the Demographic and Health Surveys. Public Health Nutr. 2014, 17, 11, 2407-2418. DOI: $\quad 10.1017 / S 1368980014000275 . \quad$ Avaliable online: https://www.ncbi.nlm.nih.gov/pubmed/?term=Trends+in+stunting+and+overweig ht+in+Peruvian+pre- 
schoolers+from+1991+to+2011\%3A+findings+from+the+Demographic+and+He alth+Surveys.+Public+Health+Nutr (Accessed on 26 June 2018).

65. Loret de Mola C, Quispe R, Valle GA, Poterico JA. Nutritional transition in children under five years and women of reproductive age: a 15-years trend analysis in Peru. PloS One. 2014, 9, 3, e92550. DOI: 10.1371/journal.pone.0092550. Avaliable online: https://www.ncbi.nlm.nih.gov/pubmed/?term=Nutritional+transition+in+children+ under+five+years+and+women+of+reproductive+age $\% 3 A+a+15-$ years+trend+analysis+in+Peru.+PloS+One (Accessed on 26 June 2018).

66. Finucane, M.M.; Stevens, G.A.; Cowan, M.J.; Danaei, G.; Lin, J.K.; Paciorek, C.J.; Singh, G.M.; Gutierrez, H.R.; Lu, Y.; Bahalim, A.N.; et al. National, regional, and global trends in body-mass index since 1980: systematic analysis of health examination surveys and epidemiological studies with 960 country-years and 9.1 million participants. Lancet. 2011, 377, 9765, 557-67. DOI: $\quad$ 10.1016/S0140-6736(10)62037-5. Avaliable online: https://www.ncbi.nlm.nih.gov/pubmed/?term=National\%2C+regional\%2C+and+ global+trends+in+bodymass+index+since $+1980 \% 3 \mathrm{~A}+$ systematic+analysis+of+health+examination+sur veys+and+epidemiological+studies+with+960+countryyears+and+9.1+million+participants.+Lancet (Accessed on 26 June 2018).

67. Stevens, G.A.; Singh, G.M.; Lu, Y.; Danaei, G.; Lin, J.K.; Finucane, M.M.; Bahalim, A.N.; Mclntire, R.K.; Gutierrez, H.R.; Cowan, M.; et al. National, regional, and global trends in adult overweight and obesity prevalences. Popul. Health Metr. 2012, 10, 1, 22. DOI: 10.1186/1478-7954-10-22. Avaliable online: https://www.ncbi.nlm.nih.gov/pubmed/23167948 (Accessed on 26 June 2018). 
68. Mielke, G,I.; Hallal, P.C.; Rodrigues, G.B.A.; Szwarcwald, C.L.; Santos, F.V.; Malta, D.C. Physical activity and television viewing among Brazilian adults. National Health Survey 2013. Epidemiol. Serv. Saúde. 2015, 24, 2, 277-286. DOI: 10.5123/S1679-49742015000200010. Avaliable online: http://www.scielo.br/scielo.php?script=sci_arttext\&pid=S223796222015000200277 (Accessed on 26 June 2018).

69. Vigitel Brasil. Vigilância de fatores de risco e proteção para doenças crônicas por inquérito telefônico. 2014. Available at: http://bvsms.saude.gov.br/bvs/publicacoes/vigitel_brasil_2014.pdf. (Acessed on 25 May 2018). 